\title{
Article \\ Gold Nanoframe Array Electrode for Straightforward Detection of Hydrogen Peroxide
}

\author{
Agnes Purwidyantri ${ }^{1,2}{ }^{-}$, Ya-Chung Tian ${ }^{3}\left(\mathbb{D}\right.$, Gardin Muhammad Andika Saputra ${ }^{4}\left(\mathbb{C}\right.$, Briliant Adhi Prabowo ${ }^{1,5}$, \\ Hui-Ling Liu ${ }^{6}$, Chia-Ming Yang ${ }^{6,7,8,9, *(\mathbb{D})}$ and Chao-Sung Lai ${ }^{3,6,8,10,11, * \mathbb{D}}$
}

1 International Iberian Nanotechnology Laboratory, 4715-330 Braga, Portugal; agnes.purwidyantri@inl.int (A.P.); briliant.prabowo@inl.int (B.A.P.)

2 Research Unit for Clean Technology, Indonesian Institute of Sciences, Bandung 40135, Indonesia

3 Department of Nephrology, Chang Gung Memorial Hospital, Linkou 33305, Taiwan; dryctian@adm.cgmh.org.tw

4 Materials Engineering Department, Faculty of Mechanical and Aerospace Engineering, Bandung Institute of Technology, Bandung 40135, Indonesia; gardin.mas@gmail.com

5 Research Center for Electronics and Telecommunications, Indonesian Institute of Sciences, Bandung 40135, Indonesia

6 Department of Electronic Engineering, Chang Gung University, Taoyuan 30002, Taiwan; hll20121219@gmail.com

7 Institute of Electro-Optical Engineering, Chang Gung University, Taoyuan 33302, Taiwan

8 Biosensor Group, Biomedical Engineering Research Center, Chang Gung University, Taoyuan 33302, Taiwan

9 Department of General Surgery, Chang Gung Memorial Hospital, Linkou 33305, Taiwan

10 Department of Materials Engineering, Ming Chi University of Technology, New Taipei City 24301, Taiwan

11 Artificial Intelligence Research Center, Chang Gung University, Taoyuan 30002, Taiwan

* Correspondence: cmyang@mail.cgu.edu.tw (C.-M.Y.); cslai@mail.cgu.edu.tw (C.-S.L.)

Citation: Purwidyantri, A.; Tian, Y.-C.; Saputra, G.M.A.; Prabowo, B.A.; Liu, H.-L.; Yang, C.-M.; Lai, C.-S. Gold Nanoframe Array Electrode for Straightforward Detection of Hydrogen Peroxide. Chemosensors 2021, 9, 37. https://doi.org/ $10.3390 /$ chemosensors 9020037

Academic Editor: Alain Walcarius

Received: 24 December 2020

Accepted: 14 February 2021

Published: 16 February 2021

Publisher's Note: MDPI stays neutral with regard to jurisdictional claims in published maps and institutional affiliations.

Copyright: (c) 2021 by the authors. Licensee MDPI, Basel, Switzerland. This article is an open access article distributed under the terms and conditions of the Creative Commons Attribution (CC BY) license (https:// creativecommons.org/licenses/by/ $4.0 /)$.

\begin{abstract}
The nanostructuring of a sensing membrane is performed through colloidal nanosphere lithography (NSL) techniques with a tiny polystyrene nanobead template $100 \mathrm{~nm}$ in size. The solvent ratio adjustment has been proven to be effective in assisting the monolayer deposition of small templating particles with minimal defects. Two distinct structures, namely, a billowy gold nanostructure (BGN) where the nanobead template is left unetched and a gold nanoframe array (GNA) with a regular ring-like structure after template removal, are used for the extended-gate field-effect transistor (EGFET) electrodes. The GNA structure generates an electroactive surface area significantly ( 20\%) larger than its geometrical area as well as a greater surface roughness than the BGN. When integrated with the portable constant voltage-constant current (CVCC) FET circuitry for $\mathrm{pH}$ screening to determine the optimized measurement conditions for $\mathrm{H}_{2} \mathrm{O}_{2}$ sensing, the GNA sensing membrane also shows more improved Nernstian sensitivity at $\sim 50 \mathrm{mV} / \mathrm{pH}$ than the BGN electrode. The more optimized sensitivity is then proven using the GNA in the detection of $\mathrm{H}_{2} \mathrm{O}_{2}$, the most common representative reactive oxygen species (ROS) involved in the environment, food, and neurodegenerative diseases, such as Parkinson's and Alzheimer's diseases. The GNA electrode has a sensitivity of $70.42 \mathrm{mV} / \log \mu \mathrm{M}\left[\mathrm{H}_{2} \mathrm{O}_{2}\right]$ and a limit of detection (LoD) of $1.183 \mu \mathrm{M} \mathrm{H}_{2} \mathrm{O}_{2}$. The integrated ion sensing system employing unique, highly ordered gold array gate electrodes and a portable CVCC circuit system has shown a stable real-time output voltage signal, representing an alternative to bulky conventional FET devices for potential on-site $\mathrm{H}_{2} \mathrm{O}_{2}$ detection.
\end{abstract}

Keywords: gold nanoframe array (GNA); nanosphere lithography (NSL); ion sensor; $\mathrm{H}_{2} \mathrm{O}_{2}$ sensor; field-effect transistor (FET); constant voltage-constant current (CVCC)

\section{Introduction}

The measurement of ions in samples at low concentrations with rapid and accurate responses has been an important approach, with comprehensive impacts in various fields, such as biomedical research and diagnostics [1,2], environmental control [3,4], and 
food safety [5,6]. An ion-selective field-effect transistor (ISFET) is highly regarded as the earliest and most robust solid-state ion sensor typically incorporating an ion-selective membrane [7]. In a practical application, an extended-gate field-effect transistor (EGFET) has been widely employed as an ISFET structure alternative since it allows the direct measurement of samples only in contact with the gate part, which provides insulation and encapsulation of the device and electric connection from the solution and protects the device from liquid penetration [8]. Among the myriad of highly conductive gate materials, gold has drawn tremendous interest due to its high conductivity, excellent stability in harsh chemical reactions and the environment, and exceptional biocompatibility [9-11]. With the high price of bulk gold, the implementation of nanogold has created an economical solution for sensing material fabrication. Importantly, gold nanostructures have provided a remarkable surface area to volume ratio, which apparently reinforces signal acquisition and reduces the content of the materials required for the same surface area $[12,13]$.

Well-ordered arrays of nanoparticles have been highly recognized for their paramount properties in sensing technology applications, such as in optical [14,15], electrochemical [16], and field-effect transistor platforms [17-19]. Standard photolithography is applied to tune the nanodimensional size, shape, and interstitial spacing. However, this is a diffractionlimited approach in terms of the final resolution due to the wavelength of light used to expose the photoresist [20]. Electron-beam lithography, despite resulting in a high aspect ratio, requires long writing times and is highly expensive for producing gold nanoarrays at a $\mathrm{cm}^{2}$ scale and for mass production [21]. Moreover, the conventional lithography procedure must be conducted in a strictly controlled and high-cost clean-room facility, which requires capital investment, making it less than accessible to non-microelectronic researchers. Some alternatives have been proposed to overcome these disadvantages, such as soft lithography, which refers to the production of a mask or mold, typically with a flexible or soft substrate such as polydimethylsiloxane (PDMS) for replicating a nanoscale structure [22]. However, although soft lithography is considered inexpensive and less complicated and can be performed in a standard laboratory, elastic substrates are vulnerable to deformation, leading to nanopattern misalignment. Among these preexisting nanopatterning methods, colloidal nanosphere lithography (NSL) has appeared as a potentially inexpensive and environmentally friendly approach in producing highly periodic arrays of nanoparticles with a distinct size, combining the advantages of both top-down and bottom-up approaches. The NSL process is simply initiated by masking the substrate with a polystyrene nanobead template to pattern the underlying substrate with desired materials [23-25]. In our previous works, we successfully integrated NSL by drop casting polystyrene nanobeads (with sizes from $500 \mathrm{~nm}$ down to $100 \mathrm{~nm}$ ) onto a solid substrate with a $\mathrm{cm}^{2}$ scale area in a monolayer hexagonal close-packed arrangement. Followed by the deposition of gold thin films with different techniques, e.g., spin coating and thermal evaporation to various thicknesses, a number of gold nanoarray structures, such as gold nanohoneycombs for electrochemical and FET-based DNA sensors and metal films over nanosphere (MFoN) electrodes for surface-enhanced Raman spectroscopy (SERS) substrates with prominent sensing performance, were generated [26-28].

$\mathrm{H}_{2} \mathrm{O}_{2}$ has long been considered a reactive oxygen species found in a number of chemical reactions and biological processes applied in a wide field of studies. For instance, in food safety control [29] and environmental screening, free radical compounds can be formed in air and aquatic environments, which can cause acid rain from the oxidation of sulfur dioxide $\left(\mathrm{SO}_{2}\right)$ in hygroscopic aerosols [30]. In human health, $\mathrm{H}_{2} \mathrm{O}_{2}$ is involved in neuropathology and central nervous system impairment, such as in Parkinson's [31] and Alzheimer's [32] diseases. It has also been reported that $\mathrm{H}_{2} \mathrm{O}_{2}$ has been found as an oxidative product in living cell metabolism, with a wide range of concentrations from $\mathrm{pM}$ to $\mathrm{mM}$ [33-35]. Therefore, rapid, sensitive, and accurate $\mathrm{H}_{2} \mathrm{O}_{2}$ detection has become a crucially demanding parameter in diverse fields of application. Various strategies such as titrimetric, chemiluminescence, optical, electrochemical, and FET sensors have been reported to determine $\mathrm{H}_{2} \mathrm{O}_{2}$ concentrations [36,37]. However, most of the proposed works 
still employ large instrumentation, expensive and unstable reagents, and indirect and time-consuming procedures.

Herein, we report a demonstration of the real-time and rapid measurement of ion concentrations from $\mathrm{pH}$ and $\mathrm{H}_{2} \mathrm{O}_{2}$ detection using a highly periodic $2 \mathrm{D}$ array of gold nanostructures, namely, a gold nanoframe array (GNA) electrode, to be compared with a billowy gold nanostructure (BGN) as extended-gate field-effect transistor (EGFET) electrodes measured by a portable constant current-constant voltage (CVCC) circuit system. Nanostructuring is achieved by a low-cost NSL approach to fabricate subnanometer-scale gold nanoarrays with an extremely high electroactive area. The CVCC setup in this study is applied to eliminate the need for a bulky device and lengthy data analysis time after standard current from drain to source and voltage from gate to source $\left(\mathrm{I}_{\mathrm{DS}} \mathrm{V}_{\mathrm{GS}}\right)$ signal recording, as well as to provide stable, real-time, and rapid ion screening [38]. The integrated system successfully demonstrates improved sensitivity and straightforward, rapid, and stable real-time ion detection over a wide dynamic range.

\section{Materials and Methods}

\subsection{Materials}

Polystyrene (PS) nanospheres with a diameter of $100 \mathrm{~nm}$, phosphate-buffered saline (PBS) tablets, Au evaporation slug, and hydrogen peroxide solution $\left(\mathrm{H}_{2} \mathrm{O}_{2}\right)$ were purchased from Sigma Aldrich (St. Louis, MO, USA). Toluene, acetone, and isopropyl alcohol (IPA) for substrate cleaning were purchased from Avantor (Radnor, PA, USA). Indium tin oxide (ITO) on a glass substrate with a thickness of $0.7 \mathrm{~mm}$ and sheet resistance of $7 \Omega /$ square was purchased from Uni-Onward (Taipei, Taiwan). Potassium chloride $(\mathrm{KCl})$, sodium dodecyl sulfate (SDS), potassium ferricyanide $\left(\mathrm{K}_{3} \mathrm{Fe}(\mathrm{CN})_{6}\right)$, hydrogen chloride $(\mathrm{HCl})$, and sodium hydroxide $(\mathrm{NaOH})$ were purchased from Merck (Darmstadt, Germany). The deionized water used in the entire experiment (resistivity at $25^{\circ} \mathrm{C}=18.2 \mathrm{M} \Omega \cdot \mathrm{cm}$ ) was obtained from a Milli-Q system.

\subsection{Apparatus}

The hydrophilicity of ITO on a glass substrate was obtained through cleaning with an oxygen plasma cleaner from Harrick Plasma (New York, NY, USA). The morphological and topological properties of the electrodes were characterized by field emission-scanning electron microscopy (FE-SEM, HITACHI S-4700, Tokyo, Japan) with an energy-dispersive X-ray spectroscopy (EDX) system from Oxford Instruments (High Wycombe, UK) and atomic force microscopy (AFM, Innova B067-Bruker Corp., Camarillo, CA, USA). Cyclic voltammetry $(\mathrm{CV})$ for electroactive surface area determination was conducted using a PGSTAT101 Metrohm Autolab (Herisau, Switzerland). The ion sensing measurement was performed by a portable constant voltage-constant current (CVCC) circuit with product number BCS V2, from eBio Technology Inc. (New Taipei City, Taiwan) with a multichannel FET sensor connected to a WiFi wireless module.

\subsection{Methods}

\subsubsection{BGN and GNA Electrode Fabrication and Surface Characterization}

The electrode surface nanostructure was templated using $100 \mathrm{~nm}$ diameter polystyrene nanobeads following our previously reported studies [26,28,39]. A $5 \mathrm{~nm}$ Au film was deposited onto the nanobead-covered ITO surface through a thermal evaporation process using a $2 \mathrm{~nm} \mathrm{Cr}$ adhesion layer. The sensing area was defined in a circle area with $\mathrm{d}=2 \mathrm{~mm}$ and mounted on a printed circuit board (PCB). The substrates were divided into two groups: one group proceeded with polystyrene nanobead etching with toluene, creating a periodic gold nanoframe array (GNA), and the other group was left without nanobead etching, generating a billowy gold nanostructure (BGN). The morphological characteristics of the substrates from each stage of modification were screened with AFM and FE-SEM with EDX analysis. The electroactive surface areas of the BGN and GNA electrodes were determined 
using cyclic voltammetry $(\mathrm{CV})$ with potentials between -0.1 and $0.6 \mathrm{~V}$, tested in a solution containing $5 \times 10^{-6} \mathrm{~mol} / \mathrm{cm}^{3} \mathrm{~K}_{3}\left[\mathrm{Fe}(\mathrm{CN})_{6}\right]$ under a series of increasing scan rates.

\subsection{2. $\mathrm{pH}$ Measurement Using BGN and GNA Electrodes in the CVCC Circuit}

To investigate the influence of the $\mathrm{pH}$ of the background buffer solution, the fabricated electrodes were immersed into a solution containing $50 \mathrm{~mL}$ of $10 \mathrm{mM} \mathrm{H}_{2} \mathrm{O}_{2}$ with various $\mathrm{pH}$ values ranging from $\mathrm{pH} 4$ to $\mathrm{pH} 10$, achieved by $\mathrm{pH}$ fixation with $\mathrm{HCl}$ and $\mathrm{NaOH}$. The measurement was performed for $30 \mathrm{~min}$ for each $\mathrm{pH}$ value, and the last 10 output voltage points of the triplicate measurements using different sensing substrate produced under identical conditions, were extracted and plotted. The system was adjusted to measure 1 point per minute, and the measurement was performed with a fixed voltage across the gate and drain at $0.5 \mathrm{~V}$, and a drain current at $100 \mu \mathrm{A}$.

\subsection{3. $\mathrm{H}_{2} \mathrm{O}_{2}$ Detection using BGN and GNA Electrodes in the CVCC Circuit}

The electrodes were immersed in a series of $\mathrm{H}_{2} \mathrm{O}_{2}$ concentrations prepared in $0.01 \times \mathrm{PBS}$ (pH 7.4) as the background electrolyte with a total volume of $40 \mathrm{~mL}$. The tested $\mathrm{H}_{2} \mathrm{O}_{2}$ aliquot ranged from $10 \mu \mathrm{M}$ to $100 \mathrm{mM}$. The setup of the CVCC circuit used to record the output voltage versus time and the data point analysis is similar to the $\mathrm{pH}$ measurement mentioned above. The comprehensive experimental setup is presented in Figure 1.

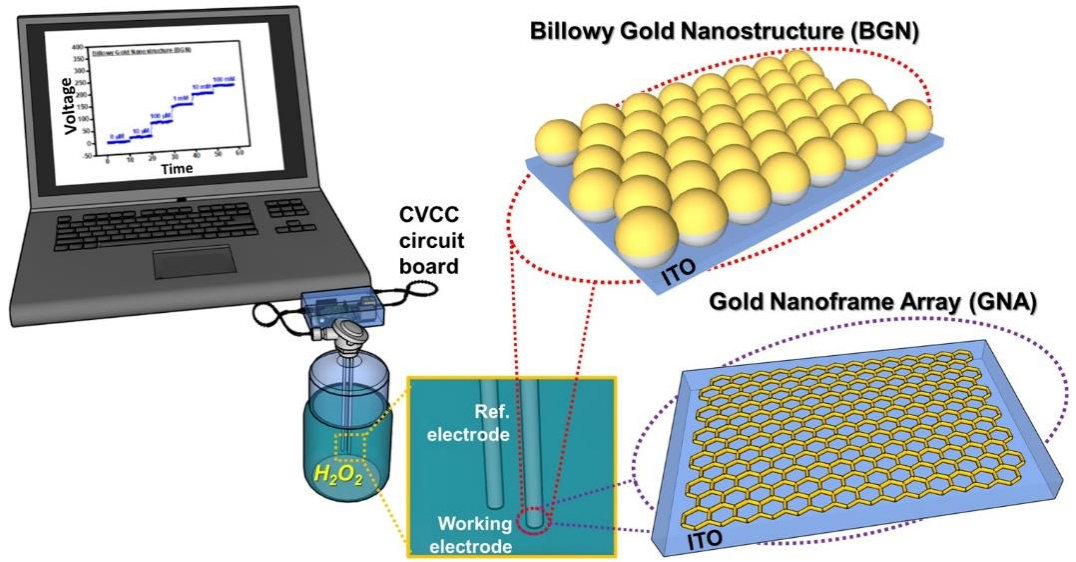

Figure 1. Schematic diagram of the real-time $\mathrm{H}_{2} \mathrm{O}_{2}$ sensing setup using a billowy gold nanostructure (BGN) and gold nanoframe array (GNA) extended-gate field-effect transistor (EGFET) integrated with a portable constant voltage-constant current (CVCC) circuit system.

\section{Results and Discussion}

The deposition of monolayer polystyrene nanobeads onto the substrate is crucial in the initial stage of nanostructuring, while tiny particles with $\mathrm{d}<200 \mathrm{~nm}$ exhibit a high tendency for forming clusters and multilayers [40]. The step-by-step surface nanostructuring is displayed in Figure 2. Starting from the bare ITO in Figure 2a, a cleaned ITO substrate was prepared before PS nanobead deposition. The transfer of the nanobeads results in a considerably monolayer coverage with minimum template dislocations on the hydrophilic ITO substrate as shown in Figure $2 b$. In working with small particles $(d=\sim 100 \mathrm{~nm})$, an equal portion of water facilitates faster ethanol evaporation. In addition, the surface tension is dominantly governed by the solid-to-liquid ratio $(\mathrm{R})$ of the solid and liquid volume, creating a specific curvature of the liquid that should be maintained as positive [41]. In this work, we used an equal water-to-ethanol ratio of the nanobead mixture during the drop-casting method to facilitate obtaining the lowest energy configuration that leads to free diffusion of the particles across the substrate by providing a sufficient solvent amount to form a convex hull for monolayer deposition onto the substrate. Figure $2 \mathrm{c}$ showing the gold film-covered nanobeads on the ITO substrate concomitantly revalidates successful nanobead template transfer onto the ITO surface as well as the uniform Au film coverage onto it as observed in a higher resolution of SEM image than that of Figure $2 b$ before 
$\mathrm{Au}$ film deposition. In most of the previously published works, NSL is incorporated in spin-coating, drop-casting, and dip-coating of larger nanobead templates with the reported typical defect-free (nanosphere polydispersity, site randomness, point defects (vacancies), line defects (slip dislocations), and polycrystalline domains) areas in the $\mu \mathrm{m}^{2}$ range [42] With the approach of maintaining an equal solvent component ratio in the drop-casting method, we obtained a comparably high nanobead coverage area of $\sim 6 \mu \mathrm{m}^{2}$ with minimum site randomness and point defects (vacancies) using particle sizes as small as $100 \mathrm{~nm}$. Nevertheless, as shown in Figure 2c, the billowy structure was evenly formed by the $\mathrm{Au}$ film due to the thermal evaporation process. It is observed that the gold film more predominantly covers the curvatures and the interstices between adjacent nanobeads rather than directly on the ITO, as seen by the brightness contrast in the few point defect sites. A contrast is seen in Figure $2 \mathrm{~d}$ after nanobead template etching, which created a highly regular lattice of hexagonal Au nanoframes with a diameter of $\sim 80 \mathrm{~nm} /$ frame in a considerably large surface area with only a minimum number of dislocated sites.

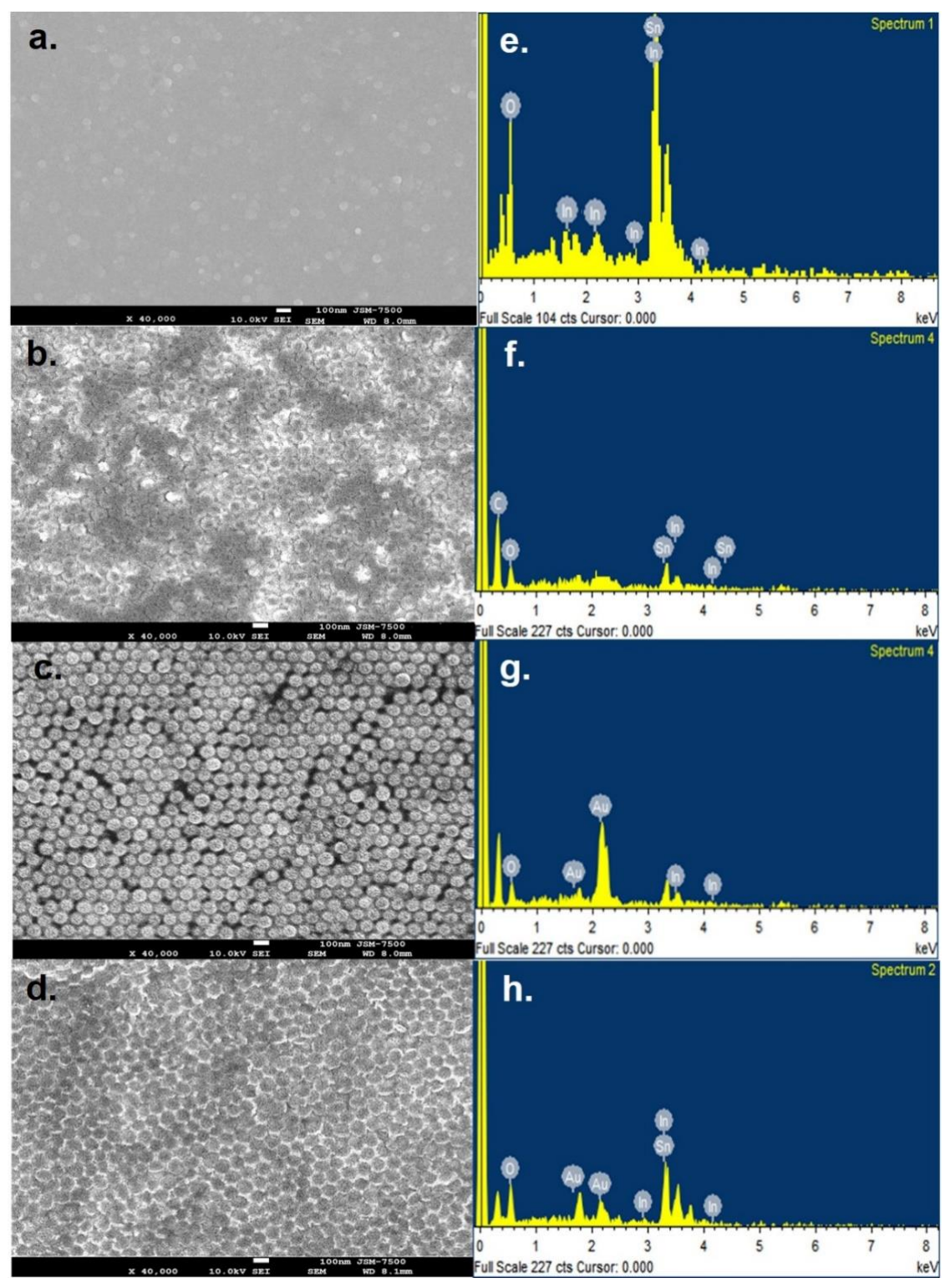

Figure 2. Field emission-scanning electron microscopy (FE-SEM) micrographs of (a) bare ITO, (b) polystyrene (PS) nanobead-covered ITO, (c) billowy gold nanostructure (BGN), (d) gold nanoframe array (GNA), and energy-dispersive X-ray spectroscopy (EDX) spectra of (e) bare ITO, (f) PS nanobead-covered ITO, (g) BGN, and (h) GNA. 
The surface nanostructuring stage is later validated with the EDX analysis. In the bare ITO substrate, the dominant elements of $\mathrm{Sn}$, In, and $\mathrm{O}$ are observed in the EDX spectrum, as shown in Figure 2e. In contrast, after nanobead deposition onto ITO, the elemental percentage of ITO is noticed to be very low, while $C$, mainly composing the polymeric nanobead, is prominent as displayed in Figure $2 \mathrm{f}$. The compositional analysis further shows that the Au particle percentage in BGN, as shown in Figure $2 \mathrm{~g}$, is nearly twice lower (with a value of $16.84 \%$ ) than that in GNA, as shown in Figure $2 \mathrm{~h}$, which reaches the value of $30.64 \%$. The honeycomb-like nanoframe array results from the highly regular and repetitive evaporation of gold in a considerably large area with a significant gold element percentage, indicating the suitability of the process for high-throughput fabrication. The overall NSL procedures only require less than 5 min to simultaneously deposit the monolayer PS nanobead onto two targeted ITO substrates. The reproducibility of the BGN and GNA electrodes' morphology under different production batches is presented in FE-SEM graphs in Figure S1 (Supplementary Information).

The topological observation by AFM denotes that the BGN structure in Figure 3a exhibits a less spikey texture than the GNA structures that have noticeable protruding spicules, as shown in Figure 3b, mostly formed by the Au film that filled the void between the two nanobead templates after the etching process. This topography is linearly associated with the surface roughness properties, given by the Rq values of $4.71 \mathrm{~nm}$ for BGN and $7.32 \mathrm{~nm}$ for GNA. The higher surface roughness of GNA is significantly assisted by the etching of the templating particles and the strong adhesion of thermally evaporated gold, leaving firm regular ring-like arrays that are potentially beneficial for improved electron transport, ion penetration, and molecular entrapment.
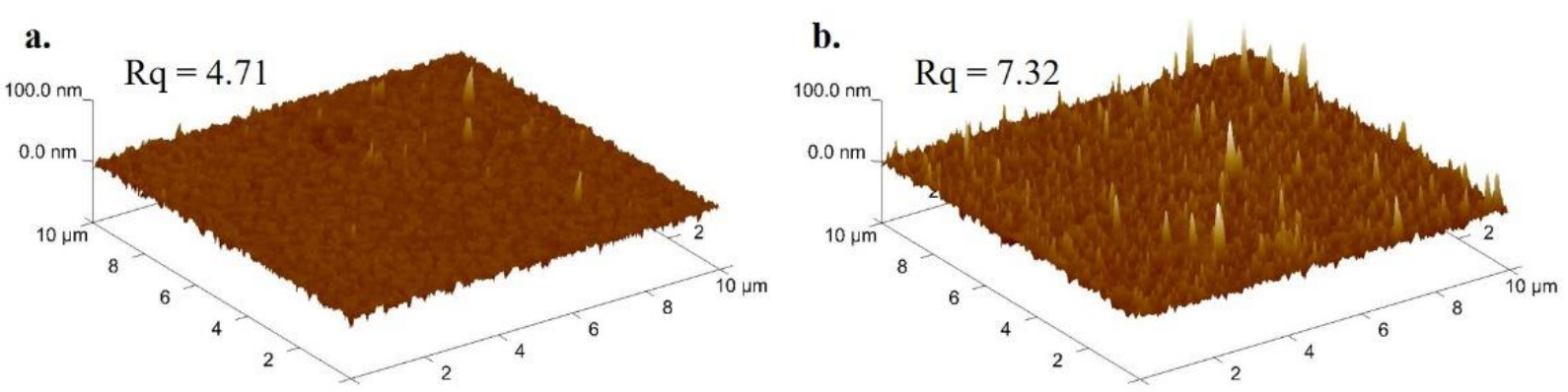

Figure 3. Atomic force microscopy (AFM) surface roughness profiling of (a) billowy gold nanostructure (BGN) and (b) gold nanoframe array (GNA) structures.

In addition to determining the distinct $\mathrm{Au}$ array configuration and the Au particle percentage, surface roughness measurements were performed to validate the total usable nanostructured surface area for a larger sensing site as well as to overcome the challenge of ion interference during the measurement [43]. The two nanostructures were then subjected to cyclic voltammetry analysis using an ionic redox probe at a series of scan rates. In all the ITO, BGN, and GNA electrodes, as seen in Figure $4 \mathrm{a}-\mathrm{c}$, the peak current gradually increased with increasing scan rates. The increment of the current range (y-axis) is recorded with each stage of surface modification from bare ITO, BGN, and finally, GNA structures. This finding is correlated to the transformation of the surface morphology and topology in each surface modification, from bare ITO owning a planar 2D surface, BGN with its 3D curvy structure, and finally GNA with its larger surface area produced by its regular ringlike structure. The higher surface area in GNA allows a more intense redox reaction, which consequently requires higher currents in cyclic voltammetry. As shown in Figure 4d-f, the plot of the extracted anodic currents is linear with the square root of scan rates in the range $50-800 \mathrm{mV} / \mathrm{s}$, reflecting the characteristics of a quasi-reversible diffusion-controlled 
electrode process [44]. The surface area calculation is performed using the Randles-Sevcik formula as follows $[27,45]$ :

$$
I_{p}=\left(2.69 \times 10^{5}\right) n^{\frac{3}{2}} A D_{0}^{\frac{1}{2}} C v^{\frac{1}{2}}
$$

where $I_{p}$ is the peak current, $n$ is the number of electrons transferred, $A$ is the dimensional surface area, $v$ is the scan rate, $D_{0}$ is the standard diffusion coefficient, equal to $7.6 \times 10^{-6}$ $\mathrm{cm}^{2} / \mathrm{s}$ for $\mathrm{K}_{3} \mathrm{Fe}(\mathrm{CN})_{6}$, and $\mathrm{C}$ is the concentration of the $\mathrm{K}_{3} \mathrm{Fe}(\mathrm{CN})_{6}$ redox probe in the solution. Through this calculation, we observed a gradual increment of the electroactive surface area; $0.010,0.017$, and $0.037 \mathrm{~cm}^{2}$ for the bare ITO, BGN, and GNA electrodes, respectively. A comparison is made over the original geometric area, where the GNA dramatically increases the surface area by $\sim 20 \%$. The findings adequately support the morphological properties, as well as the surface roughness analysis via FE-SEM and AFM, and the GNA structure achieves optimized surface characteristics for ionic analyte sensing.
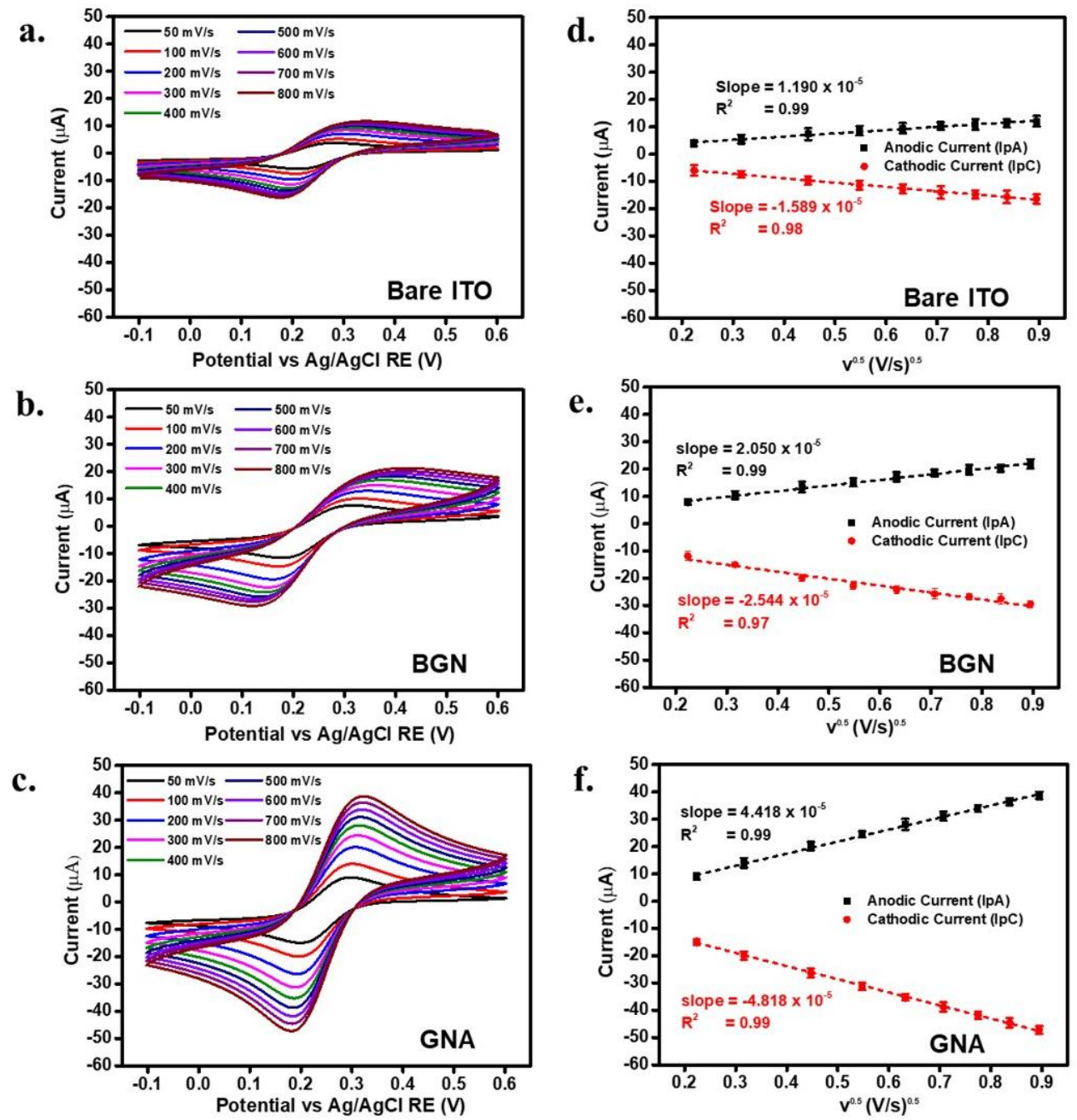

Figure 4. Cyclic voltammograms and the linear relations of the anodic peak current against the scan rate's square root of the $(\mathbf{a}, \mathbf{d})$ bare ITO, $(\mathbf{b}, \mathbf{e})$ billowy gold nanostructure $(B G N)$, and $(\mathbf{c}, \mathbf{f})$ gold nanoframe array (GNA) electrodes.

After surface characterization, the BGN and GNA electrodes were then tested in a portable CVCC circuit for the detection of $\mathrm{pH}$ to optimize the $\mathrm{H}_{2} \mathrm{O}_{2}$ measurement conditions. The CVCC circuit is explained in detail in [38]. The output voltage measurement with a series of $\mathrm{pH}$ values ranging from $\mathrm{pH} 4$ to 10 in the background solution of $10 \mathrm{mM}$ 
$\mathrm{H}_{2} \mathrm{O}_{2}$, as shown in Figure 5a,b, shows that the voltage rapidly decreased from $\mathrm{pH} 4$ to 10 in BGN and GNA. The real-time measurement from the 10-min output voltage reading at each $\mathrm{pH}$ reveals that the CVCC circuit is highly stable, as indicated by the low standard deviations in both nanostructures. The Nernstian response of the $\mathrm{pH}$ sensitivity using the GNA electrode is higher, at $\sim 50 \mathrm{mV} / \mathrm{pH}$, as shown in Figure $5 \mathrm{c}$, than that using the BGN electrode, which only reached $\sim 32 \mathrm{mV} / \mathrm{pH}$. Moreover, this result suggests that a neutral solution was the most optimized condition for the CVCC setup for $\mathrm{H}_{2} \mathrm{O}_{2}$ detection. Furthermore, by applying neutral $\mathrm{pH}$ as the background solution, we attempted to avoid the net balance charge (in the use of basis as the background solution) or the charge accumulation effects (in the use of acids as the background solution). It has been reported that the hollow structure in FET electrodes assists molecular and ionic transport at nanoscale dimensions and provides additional functional layers such as natural ionic membranes [46]. Moreover, wider diffusion of the $\mathrm{H}^{+}$ions coupled to the floating gate applied by the CVCC circuit in this measurement setup could be obtained in GNA with its highly ordered cavities than in the BGN structure where a more concentrated ionic current occurs. In contrast, in GNA, the ionic current flows freely when the electrostatic potential across the Au ring array or volume exclusion and ion adsorption is altered [47].
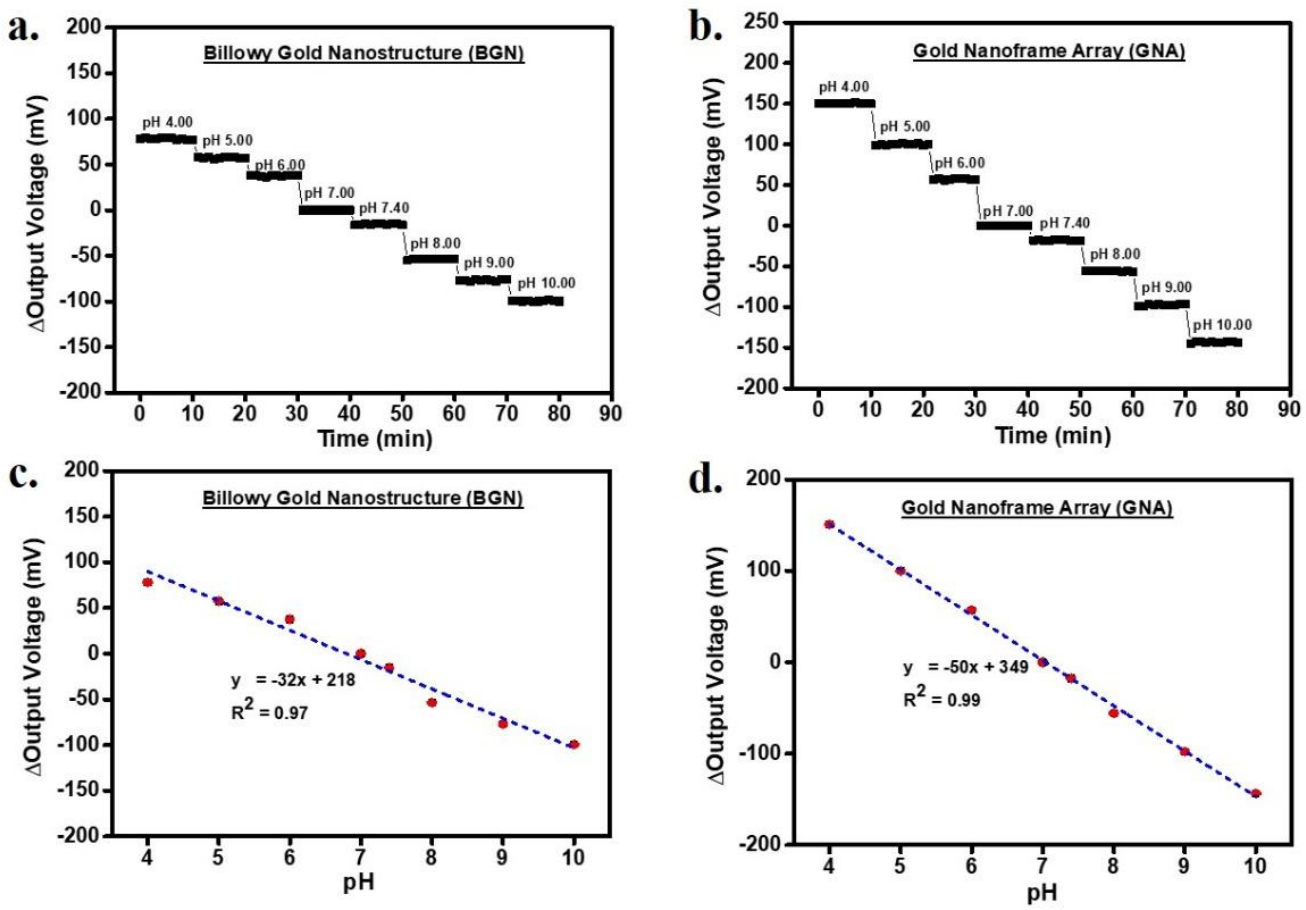

Figure 5. Real-time measurement of $\mathrm{pH}$ in $10 \mathrm{mM} \mathrm{H}_{2} \mathrm{O}_{2}$ and the respective calibration plots performed by a portable CVCC circuit using the $(\mathbf{a}, \mathbf{c})$. billowy gold nanostructure $(B G N)$ and $(\mathbf{b}, \mathbf{d})$. gold nanoframe array (GNA) electrodes.

The changes in output voltage were used to monitor the responses of the BGN and GNA electrodes upon the addition of $\mathrm{H}_{2} \mathrm{O}_{2}$ at various concentrations in real-time. The signal corresponding to $\mathrm{H}_{2} \mathrm{O}_{2}$ was extracted using the change in voltage $\left(\Delta \mathrm{V}_{\text {output }}=\mathrm{V}_{\mathrm{H} 2 \mathrm{O} 2}-\mathrm{V}_{\text {Blank }}\right)$, where $\mathrm{V}_{\text {Blank }}$ is the output voltage from the measurement of $0.01 \times \mathrm{PBS}$ without $\mathrm{H}_{2} \mathrm{O}_{2}$ and $\mathrm{V}_{\mathrm{H} 2 \mathrm{O} 2}$ is the output voltage from the measurement of $0.01 \times \mathrm{PBS}$ after the addition of a particular $\mathrm{H}_{2} \mathrm{O}_{2}$ concentration. Figure $6 \mathrm{a}, \mathrm{b}$ presents the output voltage signal from both the BGN and GNA electrodes under different $\mathrm{H}_{2} \mathrm{O}_{2}$ concentrations in $0.01 \times \mathrm{PBS}$, exhibiting a trend of increased voltage with increasing $\mathrm{H}_{2} \mathrm{O}_{2}$ concentration in a fixed duration of the measurement, which may be ascribed to the presence of positive charges after $\mathrm{H}_{2} \mathrm{O}_{2}$ is introduced onto the interface [37], which will be explained in detail later. The results indicate that the GNA electrode has a higher output signal response range than the BGN electrode based on the detection of a series of $\mathrm{H}_{2} \mathrm{O}_{2}$ concentrations over 
a dynamic range of $10 \mu \mathrm{M}$ to $100 \mathrm{mM}$, which may cover the $\mathrm{H}_{2} \mathrm{O}_{2}$ concentration range in both medical and environmental applications [33-35,48]. The sensitivity calculation derived from the linear fitting in the calibration plots in Figure $6 c$,d demonstrates that the GNA electrode presented a significantly higher sensitivity $(\sim 56 \%)$ than the BGN electrode. In the statistical analysis of $\mathrm{H}_{2} \mathrm{O}_{2}$ detection, all the standard deviations in the calibration plots were taken from triplicate measurements on an electrode fabricated and treated under similar conditions. The long-term stability of the sensors is tested in an hour measurement of $10 \mu \mathrm{M} \mathrm{H}_{2} \mathrm{O}_{2}$ in pH 7.40, as shown in Figure S2 (Supplementary Information). It is indicated that the GNA reaches faster stability than the BGN structures. Moreover, rigorous stability is also shown until the measurement completed in an hour. This supports the findings in the GNA's higher electroactive surface area than the BGN, as well as the higher surface roughness facilitating more uniform ionic distribution at the interface. The limit of detection (LoD) was approximated from the minimum concentration of $\mathrm{H}_{2} \mathrm{O}_{2}$ solution that changed the output voltage signal under CVCC measurement, equivalent to three times the average background noise in the pure background solution (blank). In this study, the LoD calculation results in a lower value of $1.183 \mu \mathrm{M}$ for GNA electrodes, while a higher LoD of $2.065 \mu \mathrm{M}$ is obtained by the BGN electrode.
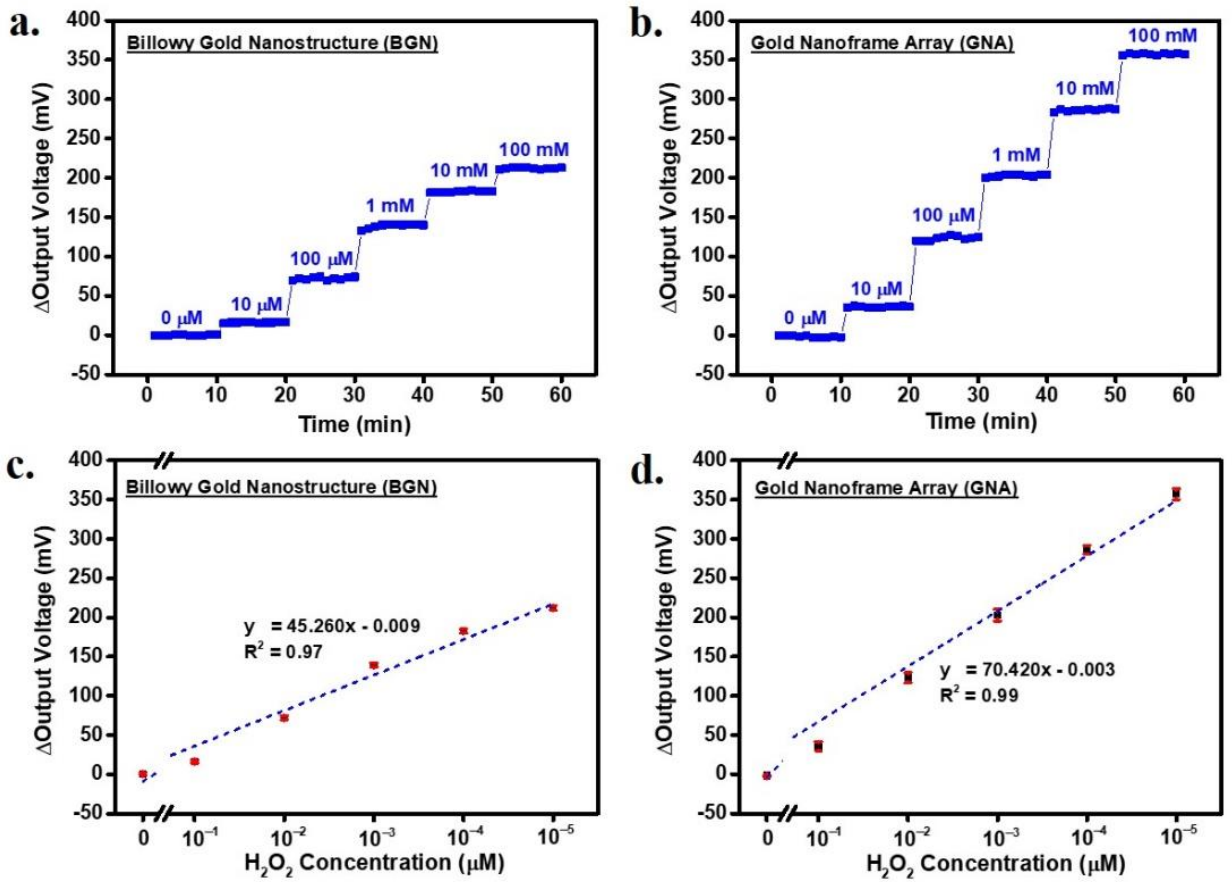

Figure 6. Real-time measurement of $\mathrm{H}_{2} \mathrm{O}_{2}$ solution and the respective calibration plots performed by a portable CVCC circuit using the $(\mathbf{a}, \mathbf{c})$. billowy gold nanostructure $(\mathrm{BGN})$ and $(\mathbf{b}, \mathbf{d})$. gold nanoframe array (GNA) electrodes.

The findings in Figure 6 are supported by a schematic mechanism of $\mathrm{H}_{2} \mathrm{O}_{2}$ detection in neutral $\mathrm{pH}$ solution as shown in Figure 7. In our FET setup, the interfacial reaction comes from several phenomena [49]. First, it is initiated from the occurrence of water electrolysis events due to the electrical polarization at the surface as follows:

$$
\begin{aligned}
& 6 \mathrm{H}_{2} \mathrm{O} \rightarrow \mathrm{O}_{2}+4 \mathrm{H}_{3} \mathrm{O}^{+}+4 \mathrm{e}^{-} \text {(water oxidation) } \\
& 4 \mathrm{H}_{2} \mathrm{O}+4 \mathrm{e}^{-} \rightarrow 2 \mathrm{H}_{2}+4 \mathrm{OH}^{-} \text {(water reduction) }
\end{aligned}
$$

Second, the self-ionization of water:

$$
2 \mathrm{H}_{2} \mathrm{O} \leftrightarrow \mathrm{H}_{3} \mathrm{O}^{+}+\mathrm{OH}^{-}
$$


Third, when the $\mathrm{H}_{2} \mathrm{O}_{2}$ is introduced to the interface, the additional oxidation reaction occurs:

$$
\mathrm{H}_{2} \mathrm{O}_{2}+2 \mathrm{H}_{2} \mathrm{O} \rightarrow \mathrm{O}_{2}+2 \mathrm{H}_{3} \mathrm{O}^{+}+2 \mathrm{e}^{-}
$$

From those reactions, the hydronium ions $\left(\mathrm{H}_{3} \mathrm{O}^{+}\right)$are highly produced and lead to the local $\mathrm{pH}$ drop. The positive charge accumulation results in the wider depletion layer on the FET channel because the Vref is a negative voltage. Subsequently, the current flow from drain (D) to source (S) drops. This state will be feedback information to increase the drain voltage to maintain the FET in the "on-state" condition and consequently triggers the increment of the output voltage.

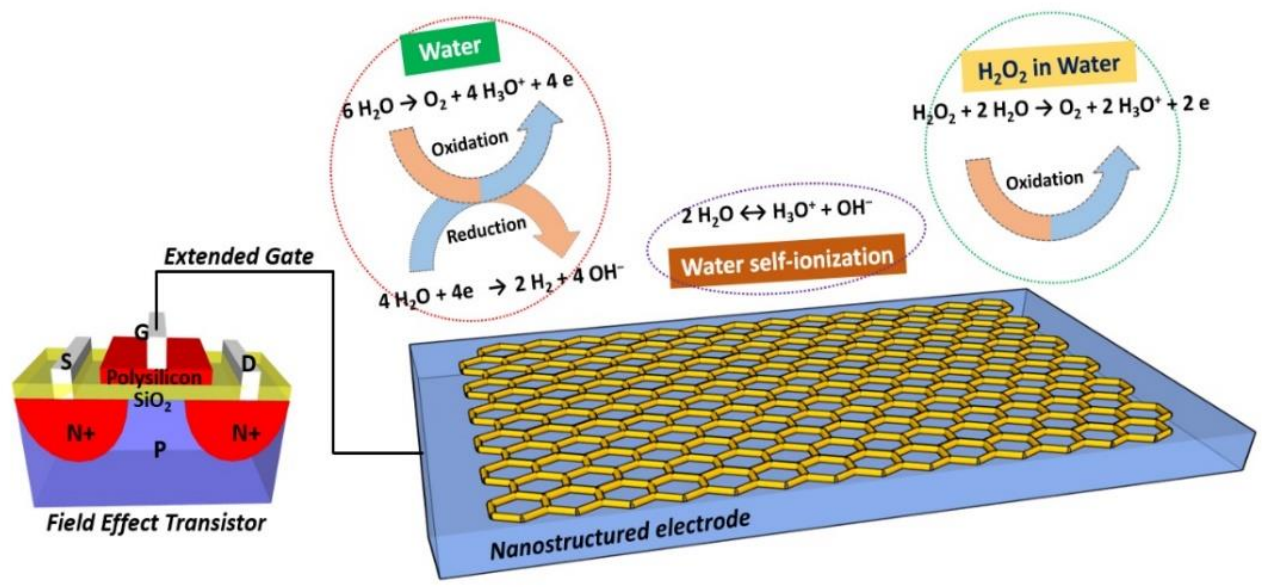

Figure 7. The water-based ion generation during $\mathrm{H}_{2} \mathrm{O}_{2}$ detection.

A comparison of the proposed EGFET sensor system for $\mathrm{H}_{2} \mathrm{O}_{2}$ detection with other systems is listed in Table 1. In terms of sensing performance, there are some aspects to be improved compared to other methods. Nevertheless, the proposed measurement system in this research using the CVCC method leads to a fully portable design and low-power sensor platform. The circuit board power and data communication are connected by a universal serial bus (USB) cable from a laptop or by WiFi connection. Moreover, the signal acquisition software is user friendly, customized, and can be fully operated from a laptop.

Table 1. Comparison of FET-based $\mathrm{H}_{2} \mathrm{O}_{2}$ sensors in terms of sensing structure, measurement technique, portability, and performance.

\begin{tabular}{|c|c|c|c|c|}
\hline FET Sensor Structure & $\begin{array}{l}\text { Measurement } \\
\text { Technique }\end{array}$ & Portability & $\begin{array}{l}\text { Quantification } \\
\text { Performance }\end{array}$ & Ref \\
\hline $\begin{array}{l}\text { Remote Pt gate electrode (electroactive } \\
\text { gate MOSFET) }\end{array}$ & Vth measurement & No & $\begin{array}{l}\text { Tunable sensitivity: } \\
\text { 221-720 } \mathrm{mV} / \text { decade }\end{array}$ & {$[50]$} \\
\hline rGO FET with a back gate & Vth measurement & No & $\sim 40 \mu \mathrm{M}$ & {$[51]$} \\
\hline $\begin{array}{l}\text { Electrochemical Field-Effect Transistor } \\
\text { (ElecFET) }\end{array}$ & Vth measurement & No & $\begin{array}{l}\text { Measurement range: } \\
1-150 \mathrm{mM}\end{array}$ & [49] \\
\hline $\begin{array}{l}\text { Polypyrrole Nanotube Embedded } \\
\text { rGO FET }\end{array}$ & $\mathrm{I}_{\mathrm{DS}}$ measurement & No & LoD: $100 \mathrm{pM}$ & [52] \\
\hline $\begin{array}{c}\text { Pd Nanoparticle at } \\
\text { Polypyrrole/Polyacrylonitrile } \\
\text { Nanofibers }\end{array}$ & $\mathrm{I}_{\mathrm{DS}}$ measurement & No & LoD: $1 \mathrm{nM}$ & {$[53]$} \\
\hline $\mathrm{M}_{\mathrm{O}} \mathrm{S}_{2} / \mathrm{rGO}$ FET & $\mathrm{I}_{\mathrm{DS}}$ measurement & No & LoD: 1 pM & {$[37]$} \\
\hline $\begin{array}{c}\text { Cytochrome c modified single-layered } \\
\text { graphene FET }\end{array}$ & $\mathrm{I}_{\mathrm{DS}}$ measurement & No & LoD: $100 \mathrm{fM}$ & {$[54]$} \\
\hline Gold nanoframe array on EGFET & Vs on CVCC system & Yes & $\begin{array}{c}\text { Sensitivity: } 70 \mathrm{mV} / \text { decade } \\
\text { LoD: } 1.183 \mu \mathrm{M}\end{array}$ & This work \\
\hline
\end{tabular}




\section{Conclusions}

This work presents a real-time, straightforward, miniaturized, and reliable sensing system for $\mathrm{pH}$ and $\mathrm{H}_{2} \mathrm{O}_{2}$ detection. Nanoscopic manipulation to create two distinct structures of ordered 2D gold arrays in subnanometer interstitial dimensions is achieved by NSL, enabling both bottom-up and top-down approaches of nanostructuring through a costeffective and simple process with potential for high-throughput fabrication. The GNA, with its regular ring-like and spikey morphology produced by polystyrene nanobead template removal after gold film deposition, shows more prominent results in ionic screening by $\mathrm{pH}$ and $\mathrm{H}_{2} \mathrm{O}_{2}$ measurements due to its higher electroactive surface area than the BGN with periodic golden ball-like Au nanofilms covering the nonetched nanobead template. The integration of nanostructured electrodes with a portable multichannel CVCC circuit has realized a real-time and stable ion sensing system as an alternative to bulky conventional FET measurement systems and opens up the possibility for multiplex in situ detection in a remote and harsh screening environment. Further development would target the application of low-dimensional gate materials, such as graphene or carbon nanotubes (CNT) targeting the improvement of the LoD and sensitivity, as well as the realization of the wireless data acquisition and full integration to the smartphone app.

Supplementary Materials: The following are available online at https:/ /www.mdpi.com/2227-904 0/9/2/37/s1, Figure S1. The FE-SEM graphs showing the reproducibility of the fabricated electrodes with BGN structure from production in (a) Batch 1 and (b) Batch 2, in tilting position; and GNA structure from production in (c) Batch 1 (d) and Batch 2, captured in the same magnification. Figure S2. A one-hour measurement of using $10 \mu \mathrm{M} \mathrm{H}_{2} \mathrm{O}_{2}$ in $\mathrm{pH} 7.40$ using BGN and GNA electrodes performed by a portable CVCC circuit.

Author Contributions: Conceptualization, A.P., Y.-C.T. and H.-L.L.; methodology, A.P. and G.M.A.S.; formal analysis, investigation, data curation, and validation, A.P., Y.-C.T., B.A.P. and G.M.A.S.; visualization, B.A.P.; writing - original draft preparation, original manuscript writing, A.P. and B.A.P.; writing-review and editing, A.P., Y.-C.T., B.A.P., C.-M.Y. and C.-S.L.; supervision, A.P., C.-M.Y. and C.-S.L. All authors have read and agreed to the published version of the manuscript.

Funding: This research was funded by Chang Gung Memorial Hospital, Taiwan under contract numbers CMRPD2K0051, CMRPD2K0171, CMRPD2I0012, and the Ministry of Science of Technology of Taiwan under contract numbers MOST:109-2221-E-182-013-MY3, 109-2622-8-182-001-TS1, 1082221-E-182-060-MY3, 108-2628-E-182-002-MY3.

Institutional Review Board Statement: Not applicable.

Informed Consent Statement: Not applicable.

Data Availability Statement: The data presented in this study are available on request from the corresponding authors.

Acknowledgments: Gardin Muhammad Andika Saputra thanks Agnes Purwidyantri and Briliant Adhi Prabowo for the technical guidance during the science internship at the Indonesian Institute of Sciences (LIPI).

Conflicts of Interest: The authors declare no conflict of interest.

\section{References}

1. Anastasios, V.; Adamos, C.; Libu, M.; Ravinder, D. Ultrathin Ion-Sensitive Field-Effect Transistor Chips with Bending-Induced Performance Enhancement. ACS Appl. Electron. Mater. 2020, 2, 2601-2610.

2. Moreddu, R.; Elsherif, M.; Adams, H.; Moschou, D.; Cordeiro, M.F.; Wolffsohn, J.S.; Vigolo, D.; Butt, H.; Cooper, J.M.; Yetisen, A.K. Integration of paper microfluidic sensors into contact lenses for tear fluid analysis. Lab Chip 2020, 20, 3970-3979. [CrossRef] [PubMed]

3. Gao, J.; Wang, Y.; Han, Y.; Gao, Y.; Wang, C.; Han, L.; Zhang, Y. Graphene-based field-effect transistors integrated with microfluidic chip for real-time $\mathrm{pH}$ monitoring of seawater. J. Mater. Sci. Mater. Electron. 2020, 31, 15372-15380. [CrossRef]

4. Machado, R.C.L.; Alexis, F.; De Sousa, A.F.B.; Sousa, D. Nanostructured and Photochromic Material for Environmental Detection of Metal Ions. Molecules 2019, 24, 4243. [CrossRef] [PubMed] 
5. Wang, D.; Wang, Z.; Wang, X.; Zhuang, X.; Tian, C.; Luan, F.; Fu, X. Functionalized Copper Nanoclusters-Based Fluorescent Probe with Aggregation-Induced Emission Property for Selective Detection of Sulfide Ions in Food Additives. J. Agric. Food Chem. 2020, 68, 11301-11308. [CrossRef] [PubMed]

6. Vivaldi, F.; SantaLucia, D.; Poma, N.; Bonini, A.; Salvo, P.; Del Noce, L.; Melai, B.; Kirchhain, A.; Kolivoška, V.; Sokolová, R.; et al. A voltammetric $\mathrm{pH}$ sensor for food and biological matrices. Sens. Actuators B Chem. 2020, 322, 128650. [CrossRef]

7. Kaisti, M. Detection principles of biological and chemical FET sensors. Biosens. Bioelectron. 2017, 98, 437-448. [CrossRef]

8. Pullano, S.A.; Critello, C.D.; Mahbub, I.; Tasneem, N.T.; Shamsir, S.; Islam, S.K.; Greco, M.; Fiorillo, A.S. EGFET-Based Sensors for Bioanalytical Applications: A Review. Sensors 2018, 18, 4042. [CrossRef]

9. Liu, Y.-L.; Jin, Z.-H.; Hu, X.-B.; Qin, Y.; Xu, J.-Q.; Fan, C.-F.; Huang, W.-H. Stretchable Electrochemical Sensor for Real-Time Monitoring of Cells and Tissues. Angew. Chem. Int. Ed. 2016, 55, 4537-4541. [CrossRef] [PubMed]

10. Melani, V.; Haddada, M.B.; Moustaoui, H.; Landoulsi, J.; Djaker, N.; Chapelle, M.L.; Spadavecchia, J. Pegylated doxorubicin gold complex: From nanovector to potential intercalant agent for biosensor applications. Front. Lab. Med. 2017, 1, 114-121. [CrossRef]

11. Gupta, R.; Rai, B. Effect of Size and Surface Charge of Gold Nanoparticles on their Skin Permeability: A Molecular Dynamics Study. Sci. Rep. 2017, 7, 45292. [CrossRef]

12. Bakshi, S.; Mehta, S.; Kumeria, T.; Shiddiky, M.J.A.; Popat, A.; Choudhury, S.; Bose, S.; Nayak, R. Rapid fabrication of homogeneously distributed hyper-branched gold nanostructured electrode based electrochemical immunosensor for detection of protein biomarkers. Sens. Actuators B Chem. 2021, 326, 128803. [CrossRef]

13. Ma, H.; Chen, Z.; Gao, X.; Liu, W.; Zhu, H. 3D hierarchically gold-nanoparticle-decorated porous carbon for high-performance supercapacitors. Sci. Rep. 2019, 9, 1-10. [CrossRef] [PubMed]

14. Song, H.Y.; Wong, T.I.; Sadovoy, A.; Wu, L.; Bai, P.; Deng, J.; Guo, S.; Wang, Y.; Knoll, W.; Zhou, X. Imprinted gold 2D nanoarray for highly sensitive and convenient PSA detection via plasmon excited quantum dots. Lab Chip 2015, 15, 253-263. [CrossRef] [PubMed]

15. Fan, X.; Hao, Q.; Jin, R.; Huang, H.; Luo, Z.; Yang, X.; Chen, Y.; Han, X.; Sun, M.; Jing, Q.; et al. Assembly of gold nanoparticles into aluminum nanobowl array. Sci. Rep. 2017, 7, 1-7. [CrossRef] [PubMed]

16. Wang, X.; Wang, Y.; Ye, X.; Wu, T.; Deng, H.; Wu, P.; Li, C. Sensing platform for neuron specific enolase based on molecularly imprinted polymerized ionic liquids in between gold nanoarrays. Biosens. Bioelectron. 2018, 99, 34-39. [CrossRef]

17. Gao, Z.; Kang, H.; Naylor, C.H.; Streller, F.; Ducos, P.; Serrano, M.D.; Ping, J.; Zauberman, J.; Carpick, R.W.; Wang, Y.J.; et al. Scalable Production of Sensor Arrays Based on High-Mobility Hybrid Graphene Field Effect Transistors. ACS Appl. Mater. Interfaces 2016, 8, 27546-27552. [CrossRef]

18. Tarasov, A.; Tsai, M.-Y.; Flynn, E.M.; Joiner, C.A.; Taylor, R.C.; Vogel, E.M. Gold-coated graphene field-effect transistors for quantitative analysis of protein-antibody interactions. 2D Mater. 2015, 2, 044008. [CrossRef]

19. Ban, T.; Uenuma, M.; Migita, S.; Okamoto, N.; Ishikawa, Y.; Uraoka, Y.; Yamashita, I.; Yamamoto, S.-I. One-dimensional array of gold nanoparticles fabricated using biotemplate and its application to fine FET. Jpn. J. Appl. Phys. 2018, 57, 06HC05. [CrossRef]

20. Paik, S.; Kim, G.; Chang, S.; Lee, S.; Jin, D.; Jeong, K.-Y.; Lee, I.S.; Lee, J.; Moon, H.; Lee, J.; et al. Near-field sub-diffraction photolithography with an elastomeric photomask. Nat. Commun. 2020, 11, 805. [CrossRef]

21. Acikgoz, C.; Hempenius, M.A.; Huskens, J.; Vancso, G.J. Polymers in conventional and alternative lithography for the fabrication of nanostructures. Eur. Polym. J. 2011, 47, 2033-2052. [CrossRef]

22. Qin, D.; Xia, Y.; Whitesides, G.M. Soft lithography for micro- and nanoscale patterning. Nat. Protoc. 2010, 5, 491-502. [CrossRef]

23. Xu, X.; Yang, Q.; Wattanatorn, N.; Zhao, C.; Chiang, N.; Jonas, S.J.; Weiss, P.S. Multiple-Patterning Nanosphere Lithography for Fabricating Periodic Three-Dimensional Hierarchical Nanostructures. ACS Nano 2017, 11, 10384-10391. [CrossRef] [PubMed]

24. Wahle, M.; Brassat, K.; Ebel, J.; Bürger, J.; Lindner, J.K.N.; Kitzerow, H.-S. Two-dimensional switchable blue phase gratings manufactured by nanosphere lithography. Opt. Express 2017, 25, 22608. [CrossRef] [PubMed]

25. Lin, B.-C.; Ku, C.-S.; Lee, H.-Y.; Wu, A.T. Epitaxial growth of ZnO nanorod arrays via a self-assembled microspheres lithography. Appl. Surf. Sci. 2017, 414, 212-217. [CrossRef]

26. Purwidyantri, A.; Hsu, C.-H.; Yang, C.-M.; Prabowo, B.A.; Tian, Y.-C.; Lai, C.-S. Plasmonic nanomaterial structuring for SERS enhancement. RSC Adv. 2019, 9, 4982-4992. [CrossRef]

27. Purwidyantri, A.; Chen, C.-H.; Hwang, B.-J.; Luo, J.-D.; Chiou, C.-C.; Tian, Y.-C.; Lin, C.-Y.; Cheng, C.-H.; Lai, C.-S. Spin-coated Au-nanohole arrays engineered by nanosphere lithography for a Staphylococcus aureus 16S rRNA electrochemical sensor. Biosens. Bioelectron. 2016, 77, 1086-1094. [CrossRef] [PubMed]

28. Purwidyantri, A.; Kamajaya, L.; Chen, C.-H.; Luo, J.-D.; Chiou, C.-C.; Tian, Y.-C.; Lin, C.-Y.; Yang, C.-M.; Lai, C.-S. A Colloidal Nanopatterning and Downscaling of a Highly Periodic Au Nanoporous EGFET Biosensor. J. Electrochem. Soc. 2018, 165, H3170-H3177. [CrossRef]

29. Ivanova, A.S.; Merkuleva, A.D.; Andreev, S.V.; Sakharov, K.A. Method for determination of hydrogen peroxide in adulterated milk using high performance liquid chromatography. Food Chem. 2019, 283, 431-436. [CrossRef]

30. Liu, T.; Clegg, S.L.; Abbatt, J.P.D. Fast oxidation of sulfur dioxide by hydrogen peroxide in deliquesced aerosol particles. Proc. Natl. Acad. Sci. USA 2020, 117, 1354-1359. [CrossRef]

31. Liu, Y.; Bai, L.; Li, Y.; Ni, Y.; Xin, C.; Zhang, C.; Liu, J.; Liu, Z.; Li, L.; Huang, W. Visualizing hydrogen peroxide in Parkinson's disease models via a ratiometric NIR fluorogenic probe. Sens. Actuators B Chem. 2019, 279, 38-43. [CrossRef] 
32. Yang, J.; Yang, J.; Liang, S.H.; Xu, Y.; Moore, A.; Ran, C. Imaging hydrogen peroxide in Alzheimer's disease via cascade signal amplification. Sci. Rep. 2016, 6, 35613. [CrossRef] [PubMed]

33. Huang, B.K.; Sikes, H.D. Quantifying intracellular hydrogen peroxide perturbations in terms of concentration. Redox Biol. 2014, 2, 955-962. [CrossRef]

34. Di Marzo, N.; Chisci, E.; Giovannoni, R. The Role of Hydrogen Peroxide in Redox-Dependent Signaling: Homeostatic and Pathological Responses in Mammalian Cells. Cells 2018, 7, 156. [CrossRef]

35. Jacewicz, D.; Siedlecka-Kroplewska, K.; Drzeżdżon, J.; Piotrowska, A.; Wyrzykowski, D.; Tesmar, A.; Żamojć, K.; Chmurzyński, L. Method for detection of hydrogen peroxide in HT22 cells. Sci. Rep. 2017, 7, srep45673. [CrossRef]

36. Al-Hardan, N.H.; Abdul Hamid, M.A.; Shamsudin, R.; Al-Khalqi, E.M.; Kar Keng, L.; Ahmed, N.M. Electrochemical hy-drogen peroxide sensor based on macroporous silicon. Sensors 2018, 18, 716. [CrossRef] [PubMed]

37. Zheng, C.; Jin, X.; Li, Y.; Mei, J.; Sun, Y.; Xiao, M.; Zhang, H.; Zhang, Z.; Zhang, G.-J. Sensitive Molybdenum Disulfide Based Field Effect Transistor Sensor for Real-time Monitoring of Hydrogen Peroxide. Sci. Rep. 2019, 9, 759. [CrossRef]

38. Chung, W.-Y.; Lin, Y.-T.; Pijanowska, D.G.; Yang, C.-H.; Wang, M.-C.; Krzyskow, A.; Torbicz, W. New ISFET interface circuit design with temperature compensation. Microelectron. J. 2006, 37, 1105-1114. [CrossRef]

39. Purwidyantri, A.; El-Mekki, I.; Lai, C.-S. Tunable Plasmonic SERS “Hotspots” on Au-Film over Nanosphere by Rapid Thermal Annealing. IEEE Trans. Nanotechnol. 2017, 16, 551-559. [CrossRef]

40. Chau, C.F.; Melvin, T. The fabrication of macroporous polysilicon by nanosphere lithography. J. Micromech. Microeng. 2008, 18, 064012. [CrossRef]

41. Chandramohan, A.; Sibirev, N.V.; Dubrovskii, V.G.; Petty, M.C.; Gallant, A.J.; Zeze, D.A. Model for large-area monolayer coverage of polystyrene nanospheres by spin coating. Sci. Rep. 2017, 7, 40888. [CrossRef]

42. Haynes, C.L.; Van Duyne, R.P. Nanosphere Lithography: A Versatile Nanofabrication Tool for Studies of Size-Dependent Nanoparticle Optics. J. Phys. Chem. B 2001, 105, 5599-5611. [CrossRef]

43. Fakih, I.; Durnan, O.; Mahvash, F.; Napal, I.; Centeno, A.; Zurutuza, A.; Yargeau, V.; Szkopek, T. Selective ion sensing with high resolution large area graphene field effect transistor arrays. Nat. Commun. 2020, 11, 1-12. [CrossRef] [PubMed]

44. Fu, K.; Bohn, P.W. Nanopore Electrochemistry: A Nexus for Molecular Control of Electron Transfer Reactions. ACS Cent. Sci. 2017, 4, 20-29. [CrossRef] [PubMed]

45. Ferrari, A.G.-M.; Foster, C.W.; Kelly, P.J.; Brownson, D.A.C.; Banks, C.E. Determination of the Electrochemical Area of ScreenPrinted Electrochemical Sensing Platforms. Biosensors 2018, 8, 53. [CrossRef]

46. Shim, J.H.; Kim, J.; Cha, G.S.; Nam, H.; White, R.J.; White, H.S.; Brown, R.B. Glass nanopore-based ion-selective electrodes. Anal. Chem. 2007, 79, 3568-3574. [CrossRef] [PubMed]

47. Kasianowicz, J.J.; Balijepalli, A.K.; Ettedgui, J.; Forstater, J.H.; Wang, H.; Zhang, H.; Robertson, J.W. Analytical applications for pore-forming proteins. Biochim. Biophys. Acta Biomembr. 2016, 1858, 593-606. [CrossRef]

48. Anh, D.T.; Olthuis, W.; Bergveld, P. A hydrogen peroxide sensor for exhaled breath measurement. Sens. Actuators B Chem. 2005. [CrossRef]

49. Diallo, A.K.; Djeghlaf, L.; Launay, J.; Temple-Boyer, P. Modelling of Impulsional pH Variations Using ChemFET-Based Microdevices: Application to Hydrogen Peroxide Detection. Sensors 2014, 14, 3267-3283. [CrossRef]

50. Anh, D.T.; Olthuis, W.; Bergveld, P. Hydrogen peroxide detection with improved selectivity and sensitivity using constant current potentiometry. Sens. Actuators B Chem. 2003, 91, 1-4. [CrossRef]

51. Kotchey, G.P.; Allen, B.L.; Vedala, H.; Yanamala, N.; Kapralov, A.A.; Tyurina, Y.Y.; Klein-Seetharaman, J.; Kagan, V.E.; Star, A. The Enzymatic Oxidation of Graphene Oxide. ACS Nano 2011, 5, 2098-2108. [CrossRef] [PubMed]

52. Park, J.W.; Park, S.J.; Kwon, O.S.; Lee, C.; Jang, J. Polypyrrole Nanotube Embedded Reduced Graphene Oxide Transducer for Field-Effect Transistor-Type $\mathrm{H}_{2} \mathrm{O}_{2}$ Biosensor. Anal. Chem. 2014, 86, 1822-1828. [CrossRef] [PubMed]

53. Kim, W.; Shin, D.H.; Jun, J.; Kim, J.H.; Jang, J. Fabrication of Shape-Controlled Palladium Nanoparticle-Decorated Elec-trospun Polypyrrole/Polyacrylonitrile Nanofibers for Hydrogen Peroxide Coalescing Detection. Adv. Mater. Interfaces 2017, $4,1700573$. [CrossRef]

54. Lee, S.H.; Kim, K.H.; Seo, S.E.; Kim, M.I.; Park, S.J.; Kwon, O.S. Cytochrome C-decorated graphene field-effect transistor for highly sensitive hydrogen peroxide detection. J. Ind. Eng. Chem. 2020, 83, 29-34. [CrossRef] 